\title{
Factors Influencing Efficiency and Productivity of Contracted and Non-Contracted Tobacco Farmers in Zimbabwe: Case of Mount Darwin District
}

\author{
Joseph Muroiwa* Abbyssinia Mushunje Tawedzegwa Musitini \\ Department of Agricultural Economics and Extension, University of Fort Hare. P Bag X1314, Alice 5700, \\ Republic of South Africa
}

\begin{abstract}
This research was financed by the Govan Mbeki Research and Development Centre.
\section{Abstract}

This main aim of this study was to determine the factors influencing efficiency and productivity of contracted and non-contracted tobacco farmers in Mount Darwin District of Zimbabwe. Data was collected from 380 randomly sampled smallholder farmers. The Data Envelopment Analysis (DEA) was used to estimate the efficiency scores for the tobacco farmers. The Tobit model censored to zero was used to evaluate the determinants of efficiency. The results showed that gender had a negative impact on both technical efficiency and economic efficiency. The probability of one being a male was likely to reduce economic efficiency by 0.022 . However, there was a positive relationship between gender and allocative efficiency. The probability of one being a male was likely to result in increase in allocative efficient by 0.035 . The results from the study showed that contracted farmers were more productive and efficient than non-contracted farmers. The ages of the farmer and education level were not significant in influencing the economic efficiencies of the farmers. Other variables like farming experience, production model, access to extension and farm size were statistically significant in influencing the economic efficiencies of tobacco farmers. The possible policy recommendations to improve efficiency of the tobacco farmers are drawn from the research findings.
\end{abstract}

Keywords: technical efficiency, allocative efficiency; economic efficiency; data envelopment analysis, tobacco farmers, Mount Darwin District.

DOI: $10.7176 / \mathrm{JESD} / 10-10-05$

Publication date:May $31^{\text {st }} 2019$

\section{Introduction}

Although tobacco plays a critical role in the Zimbabwean economy, it is worrisome that yields per hectare remain lower than what the former white commercial farmers used to produce prior to FTLRP. According to the TIMB (2017), the former white commercial farmers used to produce yield per hectare above $2500 \mathrm{~kg}$ compared to the current figures ranging below $2000 \mathrm{~kg}$ per hectare. The lower yields could be a result of inefficiencies along the production and marketing cycles. As a result of lack of efficiencies, farmers are failing to realise their full income potentials which makes them remain trapped in seabed of income insecurities, chronic vulnerability and poverty. Improving productivity and efficiency is likely to result in tobacco farmers realising better yields per hectare, improved tobacco quality leading to higher incomes, improved welfare of the tobacco farmers and long term sustainability of the value chain. Higher efficiency and productivity is going to result in Zimbabwe regaining its former status as one of the major exporters of flue cured tobacco in the world.

The main aim of this chapter was to determine the factors that influence technical, allocative and economic efficiency of smallholder tobacco farmers in Mount Darwin District of Zimbabwe. The research findings are crucial in formulation of policy recommendations on how the deterrence to improving efficiency by smallholder tobacco farmers can be addressed.

This study outlines both empirical and theoretical literature which stems the foundation for this study. The research methodology that was used to empirically test the research questions will be presented. Matters of data reliability, validity and significant diagnostic tests were also elaborated in this section of the study.

\section{Materials and Methods}

A sample size of 380 smallholder tobacco farmers was randomly selected for the study. The farmers were stratified into contracted (293) and non-contracted farmers (87). The variations in sample sizes between contracted and noncontracted farmers were because contracted farmers account for $80 \%$ of the tobacco produced and marketed in Zimbabwe (TIMB, 2017) whilst the remainder is produced and marketed under non contract institutional arrangements. Questionnaires were used to collect data on demographics, household data, yields, prices of inputs and output as well as the production and marketing costs. Detailed information on materials and methods are outlined in the methodology chapter. 


\section{The Study Area}

This study was conducted in Mount Darwin District of Zimbabwe. Mount Darwin District is one of the districts where tobacco is the major crop grown by smallholder farmers. The detailed location map for Mount Darwin District is as shown on Figure 1 below.

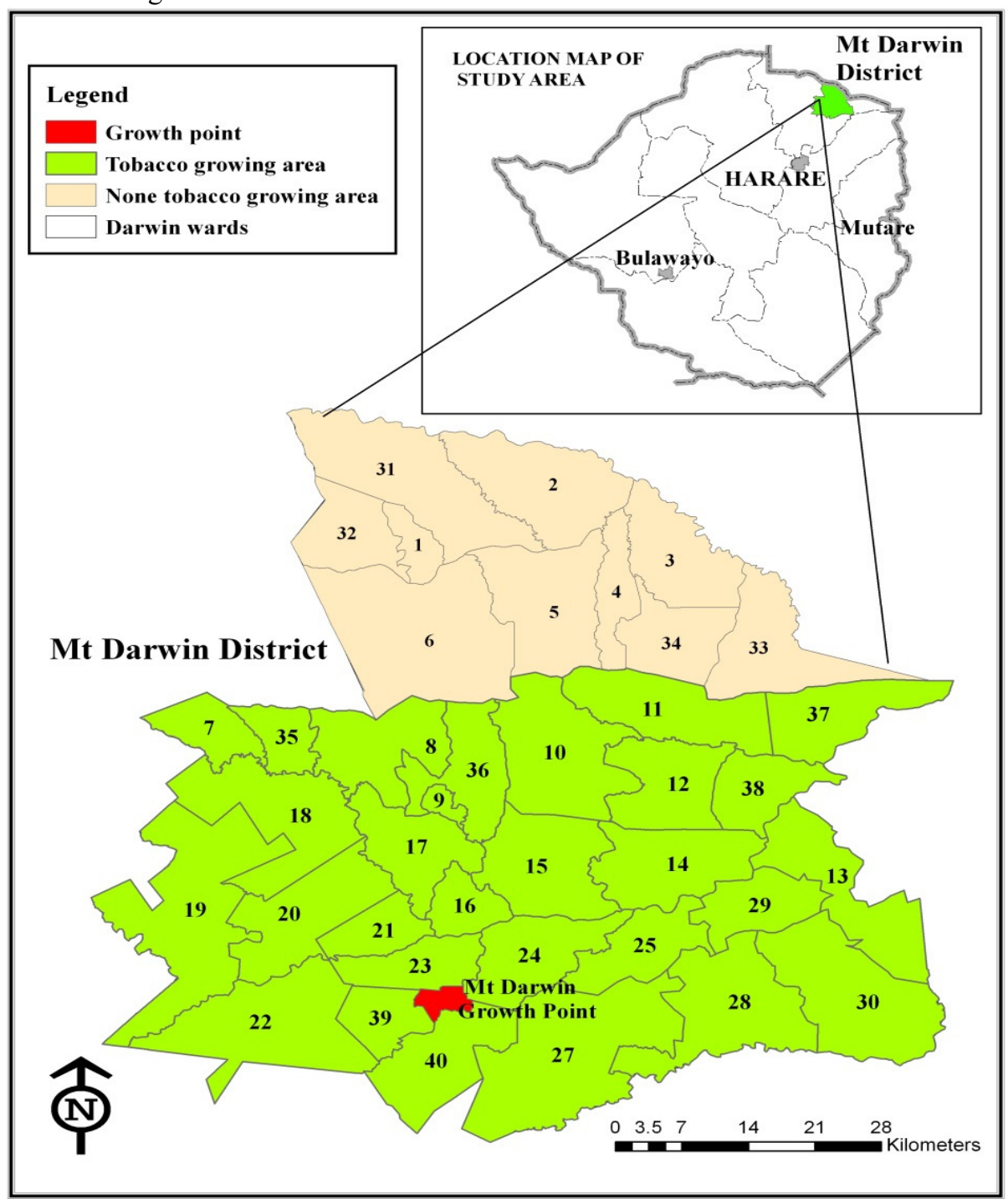

Figure 1: Location map of Mount Darwin District of Zimbabwe

\section{Sampling Procedure}

A sample size of 380 tobacco farmers comprising of 293 smallholder farmers producing under contract (77\%) and 87 producing under non contract $(23 \%)$ were randomly sampled and interviewed. The stratification of the respondents was guided by statistics from the Tobacco Industry and Marketing Board (TIMB, 2017) which revealed that $77 \%$ of the 6688 smallholder tobacco farmers in Mount Darwin produce under contract whilst the remaining $23 \%$ produce under non contract. The sample size was determined using Yamene (1967) formula at 95\% confidence level as illustrated below (Yamene, 1967).

$$
\text { Where } \quad \begin{array}{ll}
\mathrm{n}=\frac{\mathrm{N}}{1+\mathrm{Ne}^{2}} \\
\mathrm{n} & =\text { sample size } \\
\mathrm{N} & =\text { population size }(6688) \\
\mathrm{e} & =\text { allowable error of } 5 \% \text { (level of precision) }
\end{array}
$$

Basing on the above formula, a sample size of 377 farmers was obtained and rounded up to 380 .

\section{Description of variables for analysis}

\subsection{Efficiency}

The efficiency of the firm or farmer comprise of technical efficiency and allocative efficiency (Daraio \& Simar, 2007). A farmer is considered to be technical efficient if he or she is able to produce maximum output from a given 
set of inputs and technology or to produce a given level of output from the minimum amount of inputs for a given technology (Musemwa et al., 2013; Tipi et al., 2017). Allocative efficiency refers to the ability of the farmer to choose inputs in optimal proportions given their input prices (Musemwa et al., 2013). Economic efficiency is the combination of allocative and technical efficiency (Farrell, 1957). In this study, efficiency scores were measured using the Data Envelopment Analysis (DEA).

\subsection{Agricultural Productivity}

Mozumdar (2012) defined agricultural productivity as the measurement of the quantity of agricultural output produced for a given quantity of input or a set of inputs. Productivity of a production unit was also defined as the ratio of its output to its input (Lovell, 1993). Agricultural productivity is measured in different ways such as kilogrammes of tobacco per hectare or an index of numerous outputs divided by an index of numerous inputs (Wiebe, 2003) cited in (Mozumdar, 2012). Productivity is increased when the marginal change in output exceed the marginal change in the use of inputs. Productivity is unchanged if the marginal change in output increases at the same magnitude as the marginal change in inputs. In this study, productivity of the smallholder tobacco farmers was measured using kilogrammes of tobacco harvested per hectare.

\subsection{Theoretical Model}

The study builds a theoretical framework for efficiency and productivity of contract and non-contract tobacco farmers based on Contract Farming Models as discussed in literature review section. In this model, participation in tobacco farming is given as a function of demographic, human capital investment, farm-specific factors as well as socio-economic factors as highlighted below:

\section{Tobacco farming}

\section{$=f[$ demographic, human capital investment, farm specific and socio - economic factors]}

In the model above, demographic influence on tobacco contract farming participation is measured by age, household size, gender, and marital status. Among the socio-economic factors are prices, income sources, sources of credit. Proxies of farm specific influence includes farm size, soil type, access to irrigation while human capital investment include education, access to external advice, experience in farming and access to extension services. These factors influence the efficiency and productivity of contracted and non-contracted tobacco farmers.

\subsection{Model Specification}

The objective of the research was to investigate efficient determinants of tobacco farmers. The dependent variable was a limited variable henceforth limited variable models were employed with respect to the theoretical framework above and empirical models applied by Musara et al., (2011): Randela et al., (2008). The empirical model was given as:

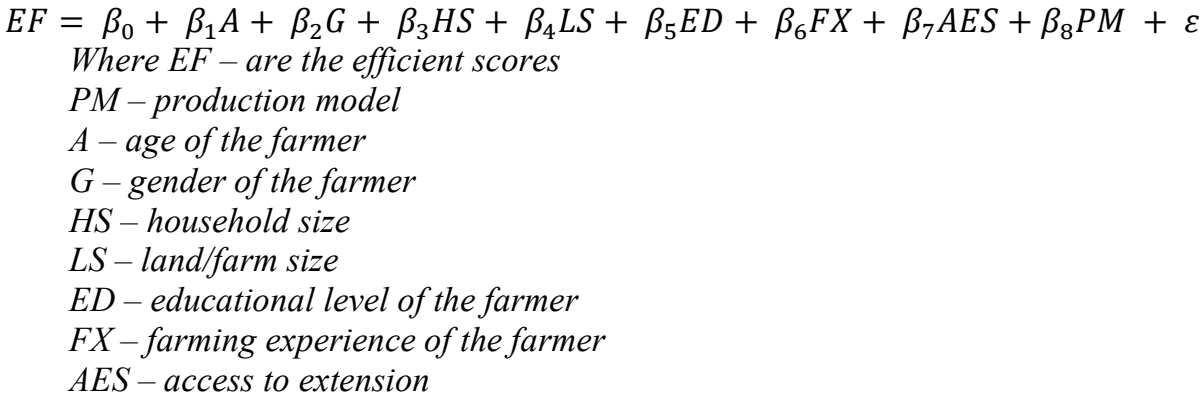

\subsection{The variables under this study}

The selection of variables was based on the literature in related studies, the researcher's perception on socioeconomic as well as institutional dynamics of the study area. Conceptual framework on the factors that are known to affect tobacco contract farming was provided by a thorough theoretical literature review. The possible determinants of efficiency in tobacco farming were identified by empirical literature review.

a. Production model $(C P)$

Production model is an independent variable in the model and the variable is explained either as contracted or non-contracted farmer. A value of one (1) is assigned to a household who participates in contract farming and zero (0) otherwise. Musara et al (2011) also employed the same variable to see the significance of contact farming in tobacco farming hence the research also includes the variable to have a comparison assessment of contracted against non-contracted tobacco farmers' efficiency. The study concluded that contracted farmers are more efficient than auction farmers; hence the expected sign is positive. 
b. Farm Specific Factors

(1) Farm/land size (LS)

This is a continuous variable measuring the size of the farm held by the household for farming purposes and is measured in hectares (ha). The variable is included in the model to assess whether farm size contributes to the efficiency and productivity of tobacco farmers. Olomola (2010) found no significant difference in farm size held by contract and non-contract farmers. In this study, there is no a prior expectation of the influence of farm size on tobacco farmers' efficiency and productivity.

c. $\quad$ Human Capital Investment

\section{(1) Educational Level (ED)}

This variable will be used as a continuous variable. The variable will be measured by the number of years of formal schooling that the farmer has attained. Musara (2011) found that, farmer's participation in contract farming was significantly influenced by the level of education as well as their efficiency and productivity. Therefore, the expected relationship is positive.

(2) Access to Extension services (AES)

The variable will be continuous, measured by the number of visits by extension agents/ officer that a farmer received per season. Bijman (2008) noted that smallholder farmers participate in contract farming because they lack technical assistance. Hence, in this study, extension services are expected to positively influence efficiency and productivity of farmers.

a. Farming Experience ( $F X)$

The variable measures the number of years the farmer has been exposed in tobacco farming and it is a continuous variable. Meshesha (2011) concluded that experience significantly influenced productivity in honey production in Sheka zone Ethiopia. Musara et al (2011) found a positive relationship between experience and efficiency. However, it can be argued that as the number of years of growing tobacco increase, the farmer will tend to be relaxed on the basis of being an expert in tobacco farming hence reducing the degree of efficiency and productivity. Therefore, in this study there is no a priori expectation of how experience impacts efficiency and productivity.

d. Demographic Factors

\section{(1) Gender $(G)$}

Gender is captured as a dummy variable with male assigned one (1) and zero (0) otherwise. Child care and responsibility for household tasks limits the agricultural activities of women and these are among the major problems why women find it difficult to indulge in farming (Nor Aini, 2003). Similar results were displayed by Benfica et al., (2006) who stressed that female headed households were less likely to engage in tobacco production, although the statistical significance was not strong. As a result of these findings the variable was included in the model to assess the heterogeneity of individual farmers, the expected relationship is positive.

\section{(2) $\quad$ Age $(A)$}

Age measured in years, it is a continuous variable that captures the age of the household head and an approximation for skills. A study by Norsidia (2007) observed that chances to participate in contract farming, efficiency and productivity actually increased with age because of little appreciation of the importance of agricultural activities by the youth in most rural set ups and takes marginal effort to expand these activities. In support of this idea, Hayrol et al (2010) noted that age heavily affect acceptance towards farming. Conversely, Mann \& Kogl (2003) did not notice differences in interest and constant positive attitude towards farming between younger and older people. Therefore, there is no a priori sign expectation in this study.

\section{(3) Household size (HS)}

This is a continuous variable measuring the size of the household members. More adult household members are expected to provide more family labour for farming activities reflecting labour intensity for production. Miyata et al., (2009): Maertens \& Swinnen (2007) found that households with more active family labour tend to participate in contract production than households with less family labour and therefore there are more efficient and productive. It is expected in this study that; larger households are more efficient and productive more than smaller households.

\section{The Econometric model}

The study employed a two-step approach to evaluate the determinants of efficiency of tobacco farmers. Firstly, the data envelopment approach was used to estimate the efficiency scores of the tobacco farmers. In the second step, the Tobit model was used to evaluate the determinants of efficiency. The study employs a cross-section of 380 tobacco farmers from Mt Darwin District. 


\section{Data Analysis}

\subsection{The Data Envelopment Analysis (DEA).}

The data envelopment analysis (DEA) is a non-parametric model (Charnes et al., 1978; Seiford \& Zhu,1998) used to measure the efficiency of peer decision making units (DMUs) with several inputs and outputs (Tipi et al., 2017; Aciti \& Podinovski, 2015). According to Helfand \& Levine (2004), DEA is one of the methods that can be used to measure a best practice production frontier. Malana \& Malano (2006) posited that DEA models can be input oriented or output oriented. The objective of the input-oriented model is to minimize inputs while maintaining same level of outputs (Farrell, 1957). On the other hand, the objective of the output oriented model is to increase output with the same inputs (Tipi et al., 2017). Each of the Decision Making Units (DMUs) use different quantities of inputs to produce varying quantities of output and DEA compares each of the decision making units with the most efficient one. A farmer is said to be technically efficient if he or she optimally utilises a combination of inputs to produce a certain level of output. A DMU is said to be efficient if it gets a score of 1 and inefficient if it scores less than 1 (Hoff, 2007).

This study applied the DEA model because the method is able to accommodate multiple inputs and multiple outputs and does not require prior aggregation of the outputs or a specific functional form of the production function. Hassan \& Sanchez (2007) argue that the approach allows the analyst to select inputs and outputs depending on the managerial focus assisting in the what-if analysis. The DEA model can be used with variables of different units without the need for standardization (e.g. labour size, number of bales harvested). However, the method is not without its challenges. The problem with the DEA method is that the results cannot be interpreted with confidence if the integrity of data is violated. To avoid this problem, less data manipulation was done. Another problem of the DEA is that it does not work well with high dimensional data. The study resolved this by using less inputs and outputs so as to avoid being highly dimensional.

The DEA results differ depending on the assumptions underlying their calculations i.e. variable returns to scale (VRS) or constant returns to scale (CRS). The choice between CRS and VRS affects the shape of the envelope surface and resultantly on the number of efficient DMUs. CRS attains if proportional increase in all inputs leads to a proportional increase in output. Models that apply the CRS are called the CCR models. The CCR Model develops the Farrells efficiency measurement concept from several inputs and one output to several inputs and several outputs into one virtual input and output which gives the efficiency score. Karimazadeh (2002) argue that the CRS model is more restrictive and yields fewer numbers of efficient units and lower efficient scores as compared to the alternative VRS hence its choice for the current study. The study therefore used the input oriented CRS model.

Assume there are ' $n$ ' DMUs and the $\mathrm{j}^{\text {th }} \mathrm{DMU}, \mathrm{DMU}, \mathrm{J}$, produces s outputs $\left(\mathrm{y}_{\mathrm{ij}}, \ldots, \mathrm{y}_{\mathrm{sj}}\right)$ by using m inputs $\left(\mathrm{x}_{\mathrm{i}} \mathrm{j}, \ldots\right.$, $\mathrm{x}_{\mathrm{mj}}$ ). The efficiency score observed $\mathrm{DMU}_{0}$ is given as the optimal value to the following linear programming model

$$
\begin{aligned}
& \theta_{0}^{*}=\min _{s . t} \theta \\
& \sum_{j} \lambda_{j} x_{i j} \leq \theta x_{i 0, i=1, \ldots, m} \\
& \sum_{j} \lambda_{j} y_{r j} \geq y_{r o}, r=1, \ldots, s \\
& \lambda_{j} \geq 0, j=1, \ldots, m
\end{aligned}
$$

This is an input oriented constant return to scale (CRS) model. $\lambda_{j}$ is the intensity variable which minimizes $\theta$. The efficiency of $\mathrm{DMU}_{0}$ is determined from efficiency score $\theta_{0}^{*}$ and its slack values. If $\theta_{0}^{*}=1$ and there is no slack, $\mathrm{DMU}_{0}$ is said to be efficient. $\theta_{0}^{*}=0$ and there are non-zero slacks, $\mathrm{DMU}_{0}$ is inefficient and is regarded as weakly efficient. The weakly-efficient DMUs and efficient DMUs constitute the efficient frontier.

\subsection{The Tobit model}

In the second stage, the Tobit model (Tobin, 1958) censored to zero was used to investigate the determinants of technical efficiency from the DEA scores. The model is useful when the dependent variables are limited by a specific threshold. The Tobit model was first suggested in econometrics literature by Tobin in 1958, and can be regarded as truncated or censored regression models where expected errors are not equal to zero. DEA scores fall between the interval zero and one making the dependent variable a limited-dependent variable. Maddala (1983) and Jackson \& Fethi (2000) argue that under such circumstances, estimating the regression using the ordinary least square leads to biased parameter estimates, since OLS assumes a normal and homoscedastic distribution of the disturbance and the dependent variable. A standard Tobit model is given by the equation below:

$$
Y_{i}^{*}=\alpha+X_{i} \beta+\varepsilon_{i}, i=1,2, \ldots, n \quad(5)
$$

where $\mathrm{y}^{*}{ }_{\mathrm{i}}$ is a latent response variable, $\mathrm{X}_{\mathrm{i}}$ is an observed $1 \times \mathrm{k}$ vector of explanatory variables, and $\varepsilon_{\mathrm{i}} \sim \mathrm{N}(0$, $\sigma^{2}$ ) and is independent of $X_{i}$ (Carson \& Sun, 2007).

$$
y= \begin{cases}y^{*} & \text { if } y^{*}<100 \\ 100 & \text { otherwise }\end{cases}
$$


where $y$ is the DEA efficiency index (after rescaling between 0 and 100) (Dhungana et al., 2004) used as the dependent variable. In this study, $X_{1}, X_{2} \ldots X_{n}$ are the independent variables that are likely to influence the efficiency of the smallholder farmers namely:

$\begin{array}{lll}\mathrm{X}_{1}= & \text { Production model } \\ \mathrm{X}_{2}= & \text { age of the farmer } \\ \mathrm{X}_{3}= & \text { gender of tobacco farmer } \\ \mathrm{X}_{4}= & \text { household size } \\ \mathrm{X}_{5}= & \text { land size } \\ \mathrm{X}_{6}= & \text { education level of tobacco farmer } \\ \mathrm{X}_{7}= & \text { farming experience of the farmer } \\ \mathrm{X}_{8}= & \text { Access to extension services (AES) } \\ \beta= & \text { is the coefficients associated with farmer specific attributes } \\ \varepsilon_{i=} & \text { error term which follows a normal distribution with a mean of zero and constant }\end{array}$

\subsection{Diagnostic tests}

The researcher performed descriptive statistics and multicollinearity, in order to determine whether the data was suffering from econometric problems such as correlations between the error terms and explanatory variables. These problems would otherwise affect the regression analysis. Diagnostic tests were performed before any regression analysis because the existence of these problems in data analysis has a significant impact on the regression analysis results.

\subsection{Descriptive statistics for the variables}

The summary of the descriptive statistics of the variables under study is as shown in Table1 below.

\section{Table.1. Descriptive statistics for the variables}

\begin{tabular}{llllll}
\hline Variable & Observations & Mean & Standard Deviation & Minimum & Maximum \\
\hline Gender (g) & 380 & 0.73 & 0.44 & 0 & 1 \\
Age (a) & 380 & 40.85 & 7.85 & 22 & 66 \\
Farming experience (fx) & 380 & 7.75 & 5.08 & 2 & 35 \\
Household size (hs) & 380 & 4.73 & 1.16 & 2 & 10 \\
Production model (pm) & 380 & 0.77 & 0.42 & 0 & 1 \\
Access to extension(aes) & 380 & 2.46 & 0.76 & 1 & 5 \\
Education level of farmer (ed) & 380 & 8.86 & 2.93 & 0 & 16 \\
Land size (ls) & 380 & 4.73 & 1.79 & 3.1 & 12 \\
& & & & & \\
\hline
\end{tabular}

Source: Survey data (2018)

\subsection{Multicollinearity test}

Multicollinearity refers to the existence of one or more linear relationships among some or all explanatory variables of a regression model (Daoud, 2017). With the problem of multicollinearity, estimates are unbiased but assessment of the relative strength of the explanatory variables and their joint effect are unreliable. As a rule of thumb, a Pearson's correlation coefficient above 0.8 signals the problem of multicollinearity (Lin, 2007). Table 2 below indicates the Pearson's correlation coefficients of the variables of interests.

Table 2. The Pearson's correlation coefficients for the variables under study.

\begin{tabular}{|l|l|l|l|l|l|l|l|l|}
\hline Variable & $\boldsymbol{G}$ & $\boldsymbol{A}$ & $\boldsymbol{F X}$ & $\boldsymbol{H S}$ & $\boldsymbol{P M}$ & $\boldsymbol{A E S}$ & $\boldsymbol{E D}$ & $\boldsymbol{L S}$ \\
\hline $\boldsymbol{G}$ & 1.0000 & & & & & & & \\
\hline $\boldsymbol{A}$ & -0.0237 & 1.0000 & & & & & & \\
\hline $\boldsymbol{F} \boldsymbol{H}$ & 0.0628 & 0.1950 & 1.0000 & & & & & \\
\hline $\boldsymbol{P S}$ & -0.0699 & 0.1673 & 0.1773 & 1.0000 & & & & \\
\hline $\boldsymbol{A E S}$ & 0.1967 & -0.1015 & 0.3897 & 0.1896 & 1.0000 & & & \\
\hline $\boldsymbol{E D}$ & -0.0799 & 0.1258 & -0.1663 & -0.0054 & -0.2525 & 1.0000 & & \\
\hline $\boldsymbol{L S}$ & 0.0941 & -0.0981 & 0.1453 & 0.0316 & 0.5275 & -0.2233 & 1.0000 & \\
\hline
\end{tabular}

Source: Survey data (2018)

The results indicate that the variables did not suffer from the problem of multicollinearity as indicated by the low values of the Pearson coefficient. As a result, all the variables were included in the estimated model for regression analysis. 


\subsection{Misspecification test}

To test for the model specification, the Ramsey regression Error Specification Test (RESET) was undertaken in this study (Ramsey, 1969). In Stata, the RESET test is used to test if there are no omitted variables in the specified model. The RESET test uses the chi-test statistic. If chi-statistic is insignificant, then the model is adequately specified (Woodridge, 2013). Table 3 below shows the Ramsey regression error specification results for the study. Table3: Ramsey regression error specification results for the study

\begin{tabular}{lll}
\hline Test & F-statistic & P-value \\
\hline Ramsey RESET & 0.35 & 0.7895 \\
\hline
\end{tabular}

Source: Survey data (2018)

The results in Table 3 above highlight that the model is correctly specified and should be accepted.

\subsection{Efficiency score frequencies from the Data Envelopment Analysis}

The efficient scores from the DEA were as presented in Table4 below.

Table4: Efficiency scores from DEA

\begin{tabular}{|c|c|c|c|c|c|c|c|c|c|}
\hline \multicolumn{10}{|c|}{ Efficiency Frequency } \\
\hline & \multicolumn{3}{|c|}{ Technical efficiency } & \multicolumn{3}{|c|}{ Allocative Efficiency } & \multicolumn{3}{|c|}{ Economic Efficiency } \\
\hline Score & Contract & Auction & Total & Contract & Auction & Total & contract & Auction & Total \\
\hline $0.00-0.10$ & 0 & 0 & 0 & 0 & 0 & 0 & 0 & 0 & 0 \\
\hline $0.11-0.20$ & 0 & 0 & 0 & 49 & 10 & 59 & 0 & 0 & 0 \\
\hline $0.21-0.30$ & 0 & 0 & 0 & 71 & 25 & 96 & 0 & 0 & 0 \\
\hline $0.31-0.40$ & 0 & 0 & 0 & 76 & 32 & 108 & 1 & 3 & 4 \\
\hline $0.41-0.50$ & 0 & 0 & 0 & 35 & 20 & 55 & 14 & 84 & 98 \\
\hline $0.51-0.60$ & 1 & 0 & 1 & 19 & 0 & 19 & 91 & 0 & 91 \\
\hline $0.61-0.70$ & 16 & 1 & 17 & 16 & 0 & 16 & 116 & 0 & 116 \\
\hline $0.71-0.80$ & 16 & 2 & 18 & 6 & 0 & 6 & 40 & 0 & 40 \\
\hline $0.81-0.90$ & 86 & 10 & 96 & 8 & 0 & 8 & 13 & 0 & 13 \\
\hline $0.91-1.00$ & 174 & 74 & 248 & 13 & 0 & 13 & 18 & 0 & 18 \\
\hline Total & 293 & 87 & 380 & 293 & 87 & 380 & 293 & 87 & 380 \\
\hline
\end{tabular}

Source: Survey data (2018)

Table5 Efficiency summary

\begin{tabular}{llll}
\hline Farming Method & Technical Efficiency & Allocative Efficiency & Economic Efficiency \\
\hline Contacted & Yes & Yes & Yes \\
Non-contracted & Yes & No & Yes \\
\hline
\end{tabular}

Source: Survey data 2018

Table 5 above highlights that generally contracted tobacco farmers are technical, allocative and economic efficient as compared to non-contracted farmers that are technically and economically inefficient. Based on these findings it can be noted that contracted farmers are more efficient compared to non-contracted farmers. This can also be supported by the results on efficiency frequency shown on Table 4above.

Table 6. Tobit regression analysis results

\begin{tabular}{|l|l|l|l|l|l|l|}
\hline Variable & \multicolumn{2}{l|}{ Technical Efficiency } & \multicolumn{2}{l|}{ Allocative Efficiency } & \multicolumn{2}{l|}{ Economic Efficiency } \\
\hline & Coefficient & $P$-value & Coefficient & $P$-value & Coefficient & $P$-value \\
\hline Gender & -0.0656 & $0.0000^{* * *}$ & 0.035 & $0.0000^{* * *}$ & -0.022 & $0.0120^{* *}$ \\
\hline Age & -0.0018 & $0.0000^{* * *}$ & 0.0057 & $0.0000^{* * *}$ & 0.0008 & 0.2230 \\
\hline farming experience & 0.0046 & $0.0000^{* * *}$ & 0.0105 & $0.0000^{* * *}$ & 0.0069 & $0.0000^{* * *}$ \\
\hline household size & -0.0123 & $0.0000^{* * *}$ & -0.0012 & 0.487 & -0.0069 & $0.0920^{*}$ \\
\hline production model & 0.0284 & $0.002^{* *}$ & 1.7783 & $0.0000^{* * *}$ & 0.2122 & $0.0000^{* * *}$ \\
\hline access to extension & 0.0263 & $0.0000^{* * *}$ & 0.0290 & $0.0000^{* * *}$ & 0.0232 & $0.0000^{* * *}$ \\
\hline educational level & 0.0092 & $0.0000^{* * *}$ & 0.0106 & $0.0000^{* * *}$ & 0.0016 & 0.3440 \\
\hline land/farm size & -0.0233 & $0.0000^{* * *}$ & 0.0044 & $0.005^{* *}$ & -0.0102 & $0.0000^{* * *}$ \\
\hline Constant & 1.3734 & 0.0000 & -1.614 & 0.0000 & 0.6335 & 0.0000 \\
\hline
\end{tabular}

$* * *=1 \%$ level of significance; $* *=5 \%$ significance level; $*=10 \%$ significance level

Source: Survey data (2018) 


\subsection{Discussion on the Tobit econometric results}

The econometric results for the Tobit model are as shown on Table6 above. The next section takes through the detailed discussion of the results.

Gender [G]

The results indicate that gender is statistically significant in explaining allocative and economic efficiency at $1 \%$ and 5\% level of significance respectively. Moreover, gender explains technical efficiency at $1 \%$ level of significance. The results showed a positive relationship between gender and allocative efficiency. This means that the probability of one being a male increase the chances of being more allocative efficient by 0.035 . However, the results from the study found that there is a negative relationship between economic efficiency and gender. The chances of one being a male reduces economic efficiency by 0.022 . This might be so because economic efficiency incorporates both technical and allocative efficiency. Gender has a negative influence on technical efficiency. These findings are also supported by Benfica et al (2006) who stressed that female headed households were less likely to engage in tobacco production.

Age [A]

The results showed that the age of the farmer [measured in years] has a negative effect on technical efficiency and a positive impact on allocative efficiency. The variable is statistically significant at $1 \%$ level of significance. However, the results showed that age does not have an influence on economic efficiency. This means that the more the age of the farmer increases the more likely he or she is to be technically inefficient since age reduces the effectiveness of an individual and the energy levels to work in the fields. However, the positive relationship between age and allocative efficiency is likely because as the age of the farmer increases, he or she will be exposed to more knowledge and experience. In support of this idea, Hayrol et al (2010) noted that age heavily affect acceptance towards farming.

Farming Experience [FX]

The research findings revealed that farming experience has a positive impact on technical, allocative and economic efficiency at $1 \%$ level of significance. This might be because farmers acquire more practical knowledge through experience and this is likely to result in improved technical, allocative and economic efficiency. This finding contrasted with Meshesha (2011) who argued that experienced tobacco farmers tend to focus more on enjoying the profits and this has a negative effect on efficiency as they may decide not to apply sufficient critical inputs like fertilisers.

Household Size [HS]

The study found that household size which is also a proxy for labour has a negative significant impact on technical and allocative. A unit increase in household size is likely to result in a $1.23 \%$ decrease in technical efficiency and 0.12 drop in allocative efficiency. This could be because large household sizes are likely to have more divergent views and conflicts leading to reduced efficiency. However, household size was not statistically significant in influencing economic efficiency.

Production Model [PM]

The findings indicate that the production model employed has a positive significant impact on efficiency. The variable is a dummy variable taking a value of 1 for contracted farmers and 0 otherwise. The results explain that the probability of one being a contracted farmer increases technical efficiency, allocative efficiency and economic efficiency by $0.0284,1.7783$ and 0.2122 respectively. The research findings from this study revealed that tobacco farmers producing under contractare more efficient than non-contracted farmers. This finding concurred with Musara et al (2011) who concluded that contracted farmers are more technically, allocatively, and economically efficient than auction farmers.

Access to Extension [AES]

Access to extension services is a measure of the rate at which farmers get assistance from experts such as extension officers and number of visitations was used as a proxy for this variable. The results indicate that there is an positive relationship between access to extension and efficiency that is technical, allocative and economic efficiency. The results showed that the probability of accessing extension services was likely to increase technical, allocative and economic efficiency by $0.0263,0.0290$ and 0.0232 respectively. This is likely because farmers access critical production and marketing information through the regular visits conducted by the extension staff which ultimately results in improved efficiency. .

Educational Level [ED]

The variable was measured by the number of years one spends at school. The results indicate that the variable is significant at explaining efficiency in tobacco farming by contracted and non-contracted farmers. There is a positive relationship between educational level and technical. The probability of increasing one's education was likely to result in 0.0106 increase in allocative efficiency. However education level was statistically insignificant in influencing economic efficiency. The research findings concurred with Nkhori (2004) who posited that education increases the ability of farmers to use their resources efficiently and the locative effect of education enhances farmers`ability to obtain, analyze and interpret information. However this contrasted with Coelli \& 
Battese (1996) who found that the farmers with more years of schooling were more technically inefficient. Land/Farm Size [LS]

This is a continuous variable measuring the size of the farm held by the household for farming purposes. The results indicate that farm size has a negative effect on technically efficiency and economic efficiency and the association is statistically significant. On the other hand, it has a positive affiliation with allocative efficiency. The negative relationship is likely because as the farm size increases the more technically demanding the farm will be since most smallholder farmers are not mechanized. The lack of mechanization by smallholder farmers is likely to make the farmers fail to cope with the size of the farm. This finding concurred with Hazarika \& Alwang (2003) who found that farm size has a positive and significant influence on allocative efficiency.

\subsection{Conclusion and Policy Implications.}

The low tobacco yields per hectare currently prevailing in smallholder tobacco value chain and low profit margins realised by the tobacco farmers can be attributed to inefficiencies by the smallholder tobacco farmers in Zimbabwe. Improving the efficiencies of the smallholder farmers can result in higher yields per hectare, improved tobacco grades which ultimately culminate to better incomes for farmers. Improved efficiency and productivity result in high foreign currency inflows and long term sustainability of the whole tobacco value chain in general.

The fact that the former white Large Scale Commercial Farmers used to produce higher yields per hectare than what the smallholder farmers currently produce implies that there is wide room for improving the efficiency and productivity among the smallholder tobacco farmers. Efficiency can be improved through minimising wastages at all stages of the production and marketing cycle. Farmers are encouraged to adopt cost effective practices such as using farm yard organic manure to supplement or substitute expensive inorganic fertilisers. Fertiliser application methods such as drilling are encouraged compared to broadcasting which results in wastages. The farmers need to work closely with their extension service providers so that they get guidance on the best agricultural practices. It is also recommended that farmers be allocated reasonable land sizes that suit their resource endowments so that the land is put to productive use.

\section{References}

Aciti, K.B. \& Podinovski, V.V.( 2015). Using data envelopment analysis for the assessment of technical efficiency of units with different specialisation: An application to Agriculture. Omega, 54, pp.72-83.

Benfica, R., Tschirley, D. \& Boughton, D.(2006). Interlinked transactions in cash cropping economies: The determinants of farmer participation and performance in the Zambesi River Valley, Mozambique. In Paper presented to the International Association of Agricultural Economists. Gold Coast, 2006.

Carson, R.T. \& Sun, Y. (2007). The Tobit model with a Non-Zero Threshold. Econometrics Journal, 00, pp.1-15.

Charnes, A., Cooper, W.W. \& Rhodes, E. (1978). Measuring efficiency of decision making units. European Journal of Operational Research, 2, pp.429-44.

Coelli, T.J. \& Battese, G.E. (1996). Identification of factors which influence the technical inefficiency of Indian farmers. Australian Journal of Resource Economics Society, 40(2), pp.1-26.

Daoud, J. (2017). Multicollinearity and Regression. Journal of Physics Conference Series.

Daraio, C. \& Simar, L. (2007). Advanced Robust \& Non-Parametric Methods in Efficiency Analysis. Methods and Applications. Springler.

Dhungana, B.R., Nuthall, P.L. \& Nartea, G.V. (2004). Measuring the economic inefficiency of Nepalese rice farms using data envelopment analysis. Australian Journal of Agricultural and Resource Economics, 48:2, pp.34769.

Farrell, M.J. (1957). The measurement of productive efficiency. Journal of the Royal Statistical Society Series, III, pp.253-90.

Hassan, K. \& Sanchez, B.(2007). Efficiency determinants and dynamic efficiency changes in Latin American banking industries. Network Financial Institute, Working Papers, No 32. Indiana University.

Hazarika, G. \& Alwang, J. (2003). Access to credit, plot size and cost inefficiency among smallholder tobacco cultivators in Malawi. Agricultural Economics, 29(1), pp.99-109.

Helfand, S.M. \& Levine, E.S. (2004). Farm Size and the determinants of Productive Efficiency in the Brazilian Centre-West. Agricultural Economics, 31(2), pp.241-49.

Hoff, A. (2007). Second Stage DEA. Comparison of approach for modelling DEA score. European Journal for Operational Research, 181, pp.425-35.

Jackson, P. \& Fethi, M. (2000). Evaluating the efficiency of Turkish commercial banks: An application of DEA and Tobin Analysis. In International DEA Symposium, 2-4July 2000. Brisbane, 2000.

Karimazadeh, M. (2002). Efficiency analysis by using Data Envelopment Analysis Model: Evidence from Indian Banks. International Journal, Latest Trends. Financial and Economic Science, 2(3), pp.228-37.

Lin. (2007). http://courses.washington.edu/urbdp520/UDP520/Lab7_MultipleRegression.pdf. [Online] [Accessed 13 March 2019]. 
Lovell, C.K. (1993). Production Frontiers and Productive Efficiency. In S. Schmidt, ed. The measurement of Productive Efficiency Techniques and Applications. Oxford. pp.04-18.

Maddala, G.S. (1983). Limited dependent and qualitative variables in econometrics. Cambridge: Cambridge University Press.

Maertens, M. \& Swinnen, J.F.M. (2007). Trade, Standards and Poverty: Evidence from Senegal. Pro-poor development in low income countries. In Food, Agriculture, Trade and Environment 25-27 October. Montpellier, 2007. Centre for Institutions and Economic Performance. Katholieke Universitiet, Belgium.

Malana, N.M. \& Malano, H.M. (2006). Benchmarking productive efficiency of selected wheat areas in Parkistan and India using Data Envelopment Analysis. Journal of Irrigation and Drainage Engineering, 55(4), pp.38394.

Mann, S. \& Kogl, H. (2003). "On the Acceptance of Animal Production in Rural Communities". Journal of Land Use Planning, 20, pp.243-52.

Meshesha, J.G. (2011). Impact of contract farming on household income of smallholder farmers: The case of organic honey production in South West Ethiopia, Sheka Zone. Wageningen University and Research Centre.

Miyata, S., Minot, N. \& Hu, D. (2009). Impact of Contract farming on income. Linking Small farmers, packers and supermarkets in China. World Bank.

Mozumdar, L. (2012). Agricultural productivity and food security in the developing world. Bangladesh Journal of Agricultural Economics, pp.53-69.

Musara, J.P., Zivenge, E., Chagwiza, G. \& Chimvuramabwe, J. (2011). Determinants of smallholder cotton contract farming participation in a recovering economy: Empirical results from Patchway District, Zimbabwe. Journal of Sustainable Development in Africa, 13(4).

Musemwa, L., Mushunje, A., Muchenje, V. \& Aghdasi, L. (2013). Factors affecting efficiency of field crop production among resettled farmers in Zimbabwe. In The 4th International Conference of the African Association of Agricultural Economists, September 22-25, 2013. Hammamet, Tunisia, 2013.

Nkhori, P.A. (2004). The impact of transaction costs on the choice of cattle markets in Mahalapye District, Botswana. University of Pretoria.

Nor Aini F. (2003). Daya saing usahawan wanita Maleyu menghadapi cabaran globalisasi. In Paper presented at the National Conference on Environmental Development Challenges. Universiti Kabangsaan Malaysia Bangi, 2003

Norsidia, M. (2007). The Agricultural Community 50 years of Malaysia Agriculture: Transformation Issue, Challenges and Direction. Gerdang Selangor: UPM Publishers.

Olomola, A.S. (2010). Enhancing productivity, income and market access of rural producers in Africa: The case of contract farming in Nigeria. In The Inaugural National Science Foundation (NSF) Joint Workshop of the African Economic Research Consortium (AERC) and the International Growth Centre (IGC). Mombasa, 2010.

Ramsey, J.B. (1969). Test for Specification Errors in Classical Linear Least Squares Analysis. Journal of the Royal Statistical Association, pp.350-71.

Randela, R., Alemu, Z.G. \& Groenewald, J.A. (2008). Factors enhancing market participation by small-scale cotton farmers. Agrekon, 47(4), pp.451-66.

Seiford, L.M. \& Zhu, J. (1998). Sensitivity Analysis of DEA Model for Simultaneous Changes in all of the data. Journal of the Operational Research Society, 49, pp.1060-71.

TIMB (2017). Tobacco Industry and Marketing Board Annual Statistical Report. Harare: Tobacco Industry and Marketing Board.

Tipi, T., Yildiz, N., Nargelecekenler, M. \& Certin, B. (2017). Measuring the technical efficiency and determinants of efficiency of rice (Oryza sativa) farms in Marmara Region, Turkey. New Zealand Journal of Crop and Horticultural Science, 37, pp.121-29.

Tobin, J. (1958). Estimation of relationships for limited dependent variables. Econometrica, 26, pp.24-26.

Wiebe, K. (2003). Linking Land Quality, Agricultural Productivity and Food Security. Agricultural Economic Report No 823. US Department of Agriculture.

Woodridge, J.M. (2013). Introductory Econometrics. 5th ed. Michigan State University. 